\title{
JEVONS E O PRINCÍPIO DA UTILIDADE MARGINAL: PESQUISA EMPÍRICA E TEORIA ECONÔMICA*
}

\author{
Recibido: 23 de mayo de 2016 - Aprobado: 19 de diciembre de 2016 \\ DOI: $10.22395 /$ seec.v20n42a3 \\ Waldemar Sobral Sampaio**
}

\section{RESUMO}

Por meio de uma análise crítica e comparativa dos tratados sobre lógica (The Principles of Science) e de economia (Theory of Political Economy), este trabalho tem por escopo produzir uma leitura do pensamento de W.S. Jevons a partir de sua definição de lógica indutiva e de sua aplicação em economia, tomando por base o principio da utilidade. O objetivo de Jevons é trazer a economia para a condição de ciência pela aplicação de uma proposta metodológica de lógica indutiva contida em seu tratado sobre o método científico (The Principles of Science). Dentro desta proposição, o princípio da utilidade pode ser concebido como uma hipótese sobre o comportamento individual, passível de verificação empírica.

\section{PALAVRAS-CHAVES}

História do pensamento econômico; Microeconomia; Metodologia da economia

\section{CLASSIFICAÇÃO JEL}

\author{
B10, B21, B41
}

\section{CONTEÚDO}

Introdução; 1. The Principles of Science: a lógica e o método científico; 2. A hipótese fundamental: o princípio da utilidade; 3. O princípio da utilidade: pesquisa empírica e teoria econômica; 4. Conclusão; Bibliografia.

Este trabalho é parte da tese de doutorado do autor: "Para Além da Utilidade Marginal: Uma Leitura Metodológica Alternativa de Jevons e Walras", defendida no ano de 2008 no Programa de Pós-Graduação em Economia da Universidade Federal do Rio de Janeiro, Rio de Janeiro, Brasil, e que teve a orientação dos professores João Luiz Pondé e Fabio Neves P de Freitas. A eles o autor agradece profundamente.

** Graduado em Economia, Universidade Católica de Goiás Goiás, Brasil. Mestre em Planejamento do Desenvolvimento, Universidade Federal do Pará, Belém, Pará, Brasil. Doutor em Teoria Econômica, Universidade Federal do Rio de Janeiro, Brasil. Professor Associado II da Faculdade de Economia, Universidade Federal do Pará, Belém, Pará, Brasil. Membro do Grupo de Educação Financeira da Amazônia, Universidade Federal do Pará, Av Augusto Corrêa, 01 - Guamá. 66075-900, Belém, Pará, Brasil, Tel: 5591 3201.8045.E mail: wsampaio@ufpa.br. 


\section{JEVONS Y EL PRINCIPIO DE LA UTILIDAD MARGINAL: INVESTIGACIÓN EMPIRICA Y TEORÍA ECONÓMICA}

\section{RESUMEN}

Por medio de un análisis crítico e comparativo de los tratados sobre lógica (The Principles of Science) y economía (Theory of Political Ecoonomy), este trabajo tiene como objetivo realizar una lectura del pensamiento de W.S Jevons a partir de su definición de lógica inductiva y de su aplicación en economía tomando como base el principio de la utilidad. El objetivo de Jevons es llevar la economía a la condición de ciencia a través de una aplicación de la lógica inductiva que se encuentra en su trabajo sobre el método científico (The Principles of Science). Dentro de esta propuesta, el principio de la utilidad puede ser concebido como una hipótesis sobre el comportamiento individual apto para verificación empírica.

\section{PALABRAS CLAVE}

Historia del pensamiento económico; Microeconomía; Metodología de la economía

\section{CLASIFICACIÓN JEL}

B10, B21, B41

\section{CONTENIDO}

Introducción; 1. The Principles of Science: la lógica y el método científico; 2. La hipótesis fundamental: el principio de la utilidad; 3. El principio de la utilidad: Investigación empírica y teoría económica; 4. Conclusión; Bibliografía.

\section{JEVONS AND THE PRINCIPLE OF MARGINAL UTILITY: EMPIRICAL RESEARCH AND ECONOMIC THEORY \\ ABSTRACT}

This paper in based on a critical and comparative analysis done over the logic treaty (Principles of Science) and economic treaty (Theory of political Economy), which objective is to analyze W.S Jevons thoughts on his definition on inductive logic and its application in economics, taking as base the profit principle. Jevons objective is to analyze economics as a science under the proposed inductive logic methodology included in his scientific method treaty (Principles of Science). Within this proposal, the profit principal can be conceived as a hypothesis for individual behavior appealable by empiric behavior.

\section{KEY WORDS}

History of Economic Thought; Microeconomics; Economic Methodology.

\section{JEL CLASSIFICATION}

B10, B21, B41

\section{CONTENT}

Introduction; 1. The Principles of Science: logic and scientific method; 2. a fundamental hypotheses: the principle of utility; 3 . the principle of utility: empirical research an economic theory; 4. Conclusions; Bibliography. 


\section{INTRODUÇÃO}

Este trabalho versa, simultaneamente, sobre História do Pensamento Econômico (HPE) e metodologia. No âmbito da primeira, o contexto histórico é o da revolução marginalista. Contudo, cabe aqui um questionamento: por que retornar à revolução marginalista? Não seria esta uma temática esgotada em função da descoberta do princípio da utilidade marginal por Jevons, Menger e Walras e sua incorporação à matriz principal da teoria econômica?

A resposta para os questionamentos supracitados é relativa. Sem dúvida, o princípio da utilidade foi uma contribuição significativa para o desenvolvimento da teoria econômica, contudo, qual foi a concepção de ciência em que o mesmo foi descoberto? Neste sentido, a revolução marginalista pode, também, ser concebida, no âmbito da metodologia, como uma tentativa de trazer a economia para uma condição de ciência, que teve no princípio da utilidade o seu elemento fundamental, conforme coloca Sampaio (2008).

O objetivo deste trabalho é resgatar a concepção de ciência e a lógica da investigação indutiva sobre as quais Jevons edificou os fundamentos da economia, contidos em seu tratado Theory of Political Economy (Jevons, 1983), cujas proposições metodológicas estão detalhadas e mais bem fundamentadas em outra obra do autor: The Principles of Science (Jevons, 1877).

Neste sentido, por meio de uma análise crítica e comparativa entre as obras supracitadas, pretende-se mostrar que Jevons tem a intenção de trazer a economia para uma condição de ciência a partir dos fundamentos contidos em seu tratado sobre o método científico. O princípio da utilidade, neste contexto, é uma hipótese fundamental sobre o comportamento econômico de um agente individual que, com muita propriedade, ilustra a pretensão do autor em sua Theory of Political Economy.

Para a devida materialização destes objetivos, este ensaio está dividido em cinco seções. Além desta introdução, a segunda versa sobre o a lógica e o método científico proposto por Jevons em seu tratado The Principles of Science. A terceira aborda o princípio da utilidade marginal como uma hipótese fundamental de aplicação da lógica indutiva por Jevons. A seguinte trata do princípio da utilidade, enquanto derivado de uma aplicação metodológica de lógica indutiva, tal como Jevons a definiu. Por fim, a conclusão destaca o princípio da utilidade no contexto de uma investigação indutiva.

\section{THE PRINCIPLES OF SCIENCE: A LÓGICA E O MÉTODO CIENTÍFICO}

A obra Theory of Political Economy é publicada pela primeira vez em 1871 e tiveram outras três edições que revisaram seu conteúdo. Para as finalidades deste trabalho, seria 
necessário um exame detalhado de seu capítulo introdutório, em que proposições de caráter metodológico são apresentadas'. Porém, para uma efetiva compreensão dos fundamentos metodológicos expostos na referida obra, é importante aprofundar a análise dos argumentos desenvolvidos em uma obra de grande relevância do autor: o The Principles of Science.

Esse livro, em sua essência, constitui um tratado sobre lógica e o método científico, tendo um escopo que vai muito além dos limites da economia política, posto que os fundamentos metodológicos defendidos por Jevons em seu trabalho sobre economia encontram-se nela expandidos em uma riqueza maior de detalhes².

O próprio Jevons, conforme coloca Schabas (1998), considera seu tratado The Principles of Science sua obra mais importante. Embora contenha muito pouco sobre economia, seus fundamentos lógicos e matemáticos permitem que se tenha uma melhor visualização sobre a introdução da matemática na economia.

Desta forma, para as finalidades deste ensaio, não é possível fazer alusão aos fundamentos de Jevons sobre a questão metodológica na economia política sem ampliar sua dimensão para o contexto da lógica.

A primeira edição do The Principles of Science veio a público em 1873 e sua última revisão data de 1877. Esse tratado de lógica de Jevons é capaz de conjugar beleza e simplicidade ao mesmo tempo. O coração da referida obra é o Livro IV que versa sobre a investigação indutiva, que constitui o núcleo da argumentação exposta ao longo de toda obra ${ }^{3}$.

Para a correta caracterização da posição metodológica de Jevons é necessário atentar que, antes de mais nada, a noção de indução tal como entendida por ele se diferencia da que é utilizada por Mill (1843) em seu A System of Logic ${ }^{4}$.

Neste sentido, é pertinente fazer alusão a Keynes (1921) em seu A Treatise on Probability, quando este afirma que o processo de investigação indutiva esteve

As proposições se referem à definição, ao método e ao caráter eminentemente matemático da economia enquanto ciência.

2 Considerando que a parte introdutória da obra Theory of Political Economy trata da proposta metodológica do autor de forma superficial, um aprofundamento desta questão, necessariamente, para o tratado de lógica de Jevons.

3 As partes que antecedem o livro quarto versam sobre lógica forma, indutiva e dedutiva (livro primeiro), números e probabilidade (livro segundo) e métodos de medida (livro terceiro). A sequência da obra trata de analogias e classificações (livro quinto) a mesma é concluída com algumas reflexões sobre os limites do método científico.

4 A proposta de lógica indutiva defendida por Mill (1843) é objeto do Livro III deste tratado sobre a lógica e o método científico. 
associado aos nomes de Bacon, Hume e Mill, sendo que nos escritos do primeiro e do último autor, encontra-se eivado de erros e obscuridades.

Contudo, ainda segundo Keynes, esta categoria de investigação teria avançado de forma substantiva com Jevons e Laplace. Em relação ao primeiro, além dos inúmeros exemplos sobre a questão da prática dos cientistas, Jevons ainda fez uma importante relação entre a lógica indutiva e a probabilidade.

Na leitura de Keynes, ainda em seu A Treatise on Probability, as abordagens de Bacon e Mill falharam quando deixaram de ser um referencial que ajudasse os cientistas a explicar e analisar suas práticas, bem com justificar suas ações. Neste sentido, Keynes (1921) aproxima-se de Jevons quanto este, no prefácio de seu tratado de lógica, denuncia a dissociação entre a filosofia da ciência e a prática dos cientistas.

A posição de Keynes também é compartilhada por Burris (2001), que define o The Principles of Science como uma obra que aborda os problemas da investigação e a natureza do raciocínio envolvido no método científico. Para o autor, trata-se de uma obra sobre a lógica indutiva onde esta é tida como um requisito para a ciência.

Ainda sobre o The Principles of Science, é também pertinente citar Black (1972), quando este faz referência a Ernest Nagel, o qual adverte que a obra em foco foi altamente ignorada pelos economistas. Seus fundamentos residem na edificação da lógica e da matemática e na discussão do papel de ambas no método científico. Black (1981) ainda estende seu argumento chamando atenção para o fato de que a obra refere à existência de uma relação estreita entre o sistema de lógica e a metodologia das ciências sociais.

Dessa forma, pode-se delinear a concepção de ciência e seus fundamentos metodológicos propostos por Jevons para, posteriormente, caracterizar a economia enquanto tal. A proposta do autor é trazer a economia para uma condição de ciência, colocando-a no contexto de uma lógica indutiva que, no The Principles of Science, tem suas especificidades.

O objetivo do The Principles of Science é delinear sobre os métodos gerais de investigação indutiva, os quais são considerados por Jevons como processos mais bem elaborados de investigação quantitativa e que tem seus fundamentos na lógica formal. Para as finalidades deste trabalho é fundamental investigar as leis fundamentais do pensamento, a diferença e a relação entre as lógicas indutiva e dedutiva, o papel das hipóteses no processo de investigação.

Como todo tratado sobre lógica, o autor inicia sua obra com uma investigação sobre as leis fundamentais do pensamento e o conjunto de elementos pelos quais 
determinados raciocínios são desenvolvidos. Neste caso, a investigação indutiva defendida pelo autor tem origem em tais pressupostos.

A motivação de Jevons na elaboração de tal obra é a falta de conjugação entre o crescimento das ciências físicas e um correspondente avanço da teoria do raciocínio ${ }^{5}$. Há, neste caso, para o autor, muita referência ao método, porém sem uma devida alusão ao seu significado.

Neste contexto, não havia, à época de Jevons, um trabalho mais elaborado sobre a questão do método enquanto processo de desenvolvimento de raciocínios nas referidas ciências, dando a entender que os físicos contemporâneos raciocinavam sobre seu objeto de estudo, tiravam conclusões, mas não pensavam sobre as bases lógicas de seus processos de investigação. Simultaneamente, havia neste mesmo cenário uma reação ao método indutivo puramente empírico defendido por Francis Bacon.

Alternativamente, os físicos advogavam o uso de hipóteses precedendo suas investigações. Jevons, em sua formulação, concorda com Bacon sobre a questão das bases empíricas do conhecimento, embora, em sua opinião, não seja totalmente correto crer que o método lógico derive de fatos particulares. Ao mesmo tempo, Jevons (1877) defende, concordando com os físicos de sua época, que haja uma hipótese antecipada como uma parte fundamental da investigação indutiva.

Como todo empirista, Jevons afirma que o conhecimento deriva fundamentalmente da experiência ${ }^{6}$. Usando o termo em um amplo sentido, pode-se dizer que o autor o compreende como aquilo que se sente, interna ou externamente, ou seja, um agregado de impressões recebidas a partir de vários pontos da percepção. De acordo com aquilo que a experiência expressa, existe a natureza e suas impressões, que são os poderes ativos da mente que a ciência lança mão.

Para Jevons, nenhuma parte da experiência efetivamente empregada na ciência é adquirida sem um propósito distinto. Dessa forma, não é possível trabalhar sobre fatos que não sejam úteis, ou seja, que não levem a uma prova sobre determinados resultados.

5 No prefácio da primeira edição da obra The Principles of Science, Jevons (1877, p.389), com muita propriedade, afirma: "It may be truly that the rapid progress $f$ the physical sciences during the last three centuries had not been accompanied by a corresponding advanced in the theory of reasoning. Physicists speak familiarly of Scientific Method, but they could not readily describe what they mean by that expression".

6 No início da Livro IV de seus The Principles of Science, Jevons (1877, p. 121) não deixa qualquer dúvida neste sentido ao afirmar que: "All knowledge proceeds originally from experience.... No small part of the experience actually employed in the science is acquired without any distinct purpose" 
Normalmente, existem duas fontes de experiências que são a observação e o experimento. Quando um fenômeno ocorre em torno dos sentidos e é notado no curso de sua natureza, tem-se a observação. Quando ocorre uma mudança ou uma reprodução artificial de um conjunto de condições, trata-se de uma experimentação. Com isso, Jevons afirma que existem dois tipos de práticas científicas, respectivamente: a passiva e a ativa.

Jevons tem a concepção de que a ciência existe a partir da descoberta de uma diversidade de processos que podem ser descritos de diferentes formas. Em qualquer ato de inferência, o investigador deve estar interessado em determinadas identidades como semelhança, similaridade e analogia entre dois objetos. Considerando que um fenômeno não pode ser estudado isoladamente, haverá sempre pontos de semelhança quando comparado com outros.

Burris (2001) destaca que o processo de investigação supracitado deve estar de acordo com as leis da identidade, contradição e dualidade desenvolvidas por Jevons (1877) na parte primeira de seu The Principles of Science. Os fundamentos lógicos dessas leis, por não tratarem da temática fundamental deste trabalho, não serão abordados ${ }^{7}$.

Dessa forma, a ciência, de uma maneira geral, consiste no conhecimento de um objeto a partir de outro, e na descoberta e registro de semelhanças entre ambos. Nesse sentido, Jevons (1877) admite a dificuldade que pode haver para determinar o grau de semelhança que é suficiente para garantir a qualidade de uma inferência.

Ao longo do The Principles of Science, Jevons trabalha de modo a estabelecer as bases fundamentais dos métodos indutivo e dedutivo e afirma que a dedução é a indução de forma invertida ${ }^{8}$.

Jevons acrescenta que a dedução tem por escopo desenvolver as consequências de uma determinada lei a partir do significado do seu conteúdo. No entanto, segundo o autor, de uma maneira geral, todo conhecimento é indutivo, ou seja, é possível adquiri-lo pelos sentidos, podendo-se detectar as leis às quais ele está relacionado pelo processo de raciocínio, e, a partir das mesmas, pela dedução, desenvolver suas consequências.

Diante deste fato, o autor defende que os métodos se complementam mutuamente. Considerando que a investigação científica tem por escopo estabelecer

7 Contudo, uma exposição mais bem detalhada deste assunto pode ser encontra no próprio tratado de lógica de Jevons e em Mosselmans (1998).

8 Jevons (1877, p. 207) dedica o capítulo VII de seus The Principles of Science para caracterizar a indução enquanto método. Neste sentido, o autor destaca: "Induction is, in fact, the inverse operation of deduction, and cannot be conceived to exist without the corresponding inverse operation." 
um conjunto de leis derivadas da identidade que existe entre dois objetos, tanto o método indutivo como o dedutivo, neste processo, tem uma funcionalidade.

Ao fazer uma inferência dedutiva, o resultado obtido é uma síntese que resulta de uma combinação entre duas qualidades distintas dos objetos em estudo. Levando-se em conta a investigação indutiva, esta tem um caráter muito mais analítico e, na prática, consiste no isolamento do fenômeno em estudo do mundo real, onde ele se dá em toda sua complexidade. Como ocorre na dedução, o objetivo é determinar as leis que regem o funcionamento ou o comportamento do fenômeno e suas relações com outros objetos.

Com isso, Jevons (1877) quer mostrar que, embora sejam operações inversas, a indução e a dedução não são iguais em seus graus de dificuldade. A primeira é de uma complexidade maior do que a segunda, uma vez que deriva do fato de que um determinado objeto é regido por um conjunto de leis que operam sobre ele simultaneamente, produzindo um resultado agregado.

Por fim, considerando que a investigação científica tem por escopo estabelecer leis sobre a identidade e a diferença entre dois objetos, qual a natureza destas? Ao fazer tal questionamento, Jevons (1877) está preocupado com o resultado da investigação científica que defende. Neste sentido, o autor questiona se as leis derivadas são produtos do pensamento ou refletem as propriedades de seus objetos?

Com isso, o autor indaga se a ciência é um processo de construção puramente mental ou se reflete os fundamentos materiais de seus campos de estudo. Diante desta dúvida, Jevons propõe a verificação empírica das conclusões obtidas.

Assim, a indução e a dedução têm uma relação de complementaridade e um papel específico na aquisição do conhecimento. Dessa forma, não existe processo de inferência dedutiva que não esteja de acordo com os fatos, assim como não existem conclusões indutivas que não estejam fundamentadas em hipóteses previamente elaboradas.

De acordo com o que foi colocado anteriormente, o processo de investigação indutiva consiste na conjugação de uma hipótese com as observações. Diante de um conjunto de fatos observáveis, deve-se formular uma hipótese que antecipe a relação existente entre eles. Isso significa que, posteriormente, por meio de um processo dedutivo, torna-se possível prever um determinado fenômeno, cujo sucesso depende da conjectura a ser julgada. Assim, feita a diferença entre a indução e a dedução e suas respectivas funcionalidades no processo de investigação, é possível discorrer sobre o papel das conjeturas no mesmo. 
Jevons justifica a introdução de hipóteses na investigação indutiva argumentando que esta é guiada por um conjunto de regras. Com isso, ao aplicar determinados procedimentos a um contexto onde já existem leis sob o domínio do cientista, todo o processo de inferência torna-se cada vez menos vulnerável a erros. No caso da proposta de indução de Jevons (1877), uma maneira de superar tal vulnerabilidade é lançar mão de conjecturas sobre a ordem possível dos fatos estudados. Esse tipo de conhecimento é empírico à medida que deriva da experiência prévia e direta daquele que faz a investigação.

A história das ciências, segundo Jevons, mostra que investigações de natureza hipotética e dedutiva possibilitaram a construção de um conjunto de sistemas sobre o funcionamento do universo, e que isso abriu caminho para quase todos os ramos da filosofia natural. No âmbito da lógica indutiva defendida por Jevons, as hipóteses são instrumentos importantes em função das complicadas naturezas das investigações, conforme já colocado.

Ainda na defesa da utilização de hipóteses, Jevons considera que existem observações que não são passíveis de ser testadas experimentalmente. Dessa forma, toda antecipação teórica é vantajosa. Assim, um dado fenômeno, mesmo sendo aparentemente simples, assume um grau de complexidade no contexto em que se encontra, o que redunda na impossibilidade de investiga-lo sem uma conjectura. Dessa forma, hipóteses antecipadas são capazes de tornar o objeto de investigação mais acessível ao estudo.

Os argumentos de que Jevons (1877) lança mão para justificar a utilização de hipóteses como uma parte de sua lógica indutiva mostram sua reação contra a versão puramente empírica apresentada por Bacon. Em seu The Principles of Science, o autor faz questão de colocar que Bacon era contrário à utilização de hipóteses de antecipação e que, de maneira geral, seu método correspondia a um processo de coletar e classificar fatos, cuja acumulação poderia conduzir a axiomas abstratos ou leis gerais.

Adicionalmente, Jevons ainda afirma que, apesar de haver uma suposição de que o progresso da ciência deriva da aplicação do método baconiano no século XVII, a realidade mostra que a pesquisa hipotética foi o principal instrumento desse progresso. Para o autor, a partir desta, os físicos começaram a ter resultados mais precisos em suas investigações.

Com isso, para Jevons (1877), o verdadeiro método é aquele que se inicia com os fatos e termina com eles. Ao se observar os fatos, estes sugerem, por suas propriedades, determinadas hipóteses que, se forem confirmadas, podem, por consequência, explicar outros fatos. 
No caso da não confirmação de uma hipótese, ela deve ser abandonada, embora Jevons acredite que qualquer fato novo pode motivar a volta de sua investigação. Isso significa que, embora necessários, os fatos não são a palavra final na refutação de uma conjectura. Neste processo, aquele que pesquisa ainda pode lançar mão de outras ciências que forneçam fatos novos para aquilo que está desejando investigar.

Sendo assim, quais são os critérios normativos que devem ser levados em conta na formulação de hipóteses? Para Jevons (1877), é fundamental que uma conjectura seja capaz de inferir a existência de fenômenos do mundo real, ou seja, sua concordância com os fatos é a condição necessária e suficiente para o teste de verdade.

Apesar de a norma supracitada ser o critério único de Jevons para a formulação de uma boa hipótese, este pode ser seccionado em três partes, como segue:

- Que, antes de mais nada, seja possível aplicar o método dedutivo;

- Que não haja antagonismo entre a hipótese e as leis da natureza ou da mente;

- Que haja concordância entre os fatos da observação e as consequências inferidas.

Relativamente ao primeiro critério, as verdades de uma hipótese devem estar em conformidade com os fatos do mundo real, e a primeira condição para torná-la apta à aplicação do método dedutivo é pesquisar o comportamento do objeto na perspectiva da lei que está sendo utilizada enquanto referencial teórico. Por essa razão, Jevons sinaliza que a formulação de uma hipótese não é algo fictício ou arbitrário, mas deve estar de acordo com determinadas experiências ou analogias.

Por esta razão, toda hipótese deve permitir a comparação com a experiência. Além disso, deve possuir uma definição e uma exatidão matemáticas, que permitam o cálculo preciso dos seus resultados que a tornam válidas ou não.

Contemplando o segundo critério, uma hipótese não deve ser contraditória em relação àquilo que se acredita seja verdadeiro sobre as leis da natureza e da mente. Isso envolve, necessariamente, a coerência com as regras da lógica e com o desenvolvimento corrente das demais ciências. Ela será considerada provável ou aproximadamente correta de acordo com um número suficiente de eventos que a ratificarem.

Por fim, com relação ao terceiro critério, para que uma hipótese possa ser aceita, deve haver concordância entre ela e um conjunto de fatos particulares que motivaram sua elaboração. Além disso, deve-se também esperar que uma boa hipótese forneça uma série de elementos que possibilitem antecipar outros eventos que não estejam sendo levados em consideração. Com isso, quanto mais conclusões derivarem de 
uma teoria, e na medida em que estas estiverem de acordo com os fatos, maior será a probabilidade de aquela crescer de uma forma rápida e evidente.

\section{UMA HIPÓTESE FUNDAMENTAL: O PRINCÍPIO DA UTILIDADE}

De acordo com os principais textos sobre HPE, Jevons, bem como Menger e Walras, figuram como descobridores do princípio da utilidade marginal decrescente. Contudo, a obra de Jevons, Theory of Political Economy, pode ser interpretada a partir de outros pontos de vista, como a contraposição do autor marginalista ao pensamento de Mill e a base psicológica de sua argumentação. Nesse sentido, é pertinente fazer alusão aos trabalhos de Jevons e Jevons e Paul.

Paul (1979) chama atenção para os objetivos de Jevons em sua Theory of Political Economy, nos quais considera que está presente a intenção de propor uma alternativa aos postulados de Ricardo e Mill, segundo a qual a teoria da utilidade passaria a ser o elemento central na determinação do valor.

A posição de Paul (1979) é corroborada especialmente pelo fato de que a obra Theory of Political Economy é uma constante contraposição aos postulados de Mill, tanto no nível da metodologia como no da teoria econômica. Jevons considera que o estado de atraso da economia enquanto ciência deve-se, em grande medida, ao fato de que Mill encerrou determinadas discussões e impediu o exame de novas teorias. Como exemplo, ao definir a economia como o estudo da produção e da distribuição das riquezas, Mill teria deixado de lado um elemento fundamental: o consumo da mesma.

Jevons e Jevons (1972) assinalam que a referida obra tem duas características fundamentais: a base psicológica de suas argumentações e a introdução da matemática. Do ponto de vista das bases que determinam o comportamento individual, sua fundamentação encontra-se em Bentham, para quem toda ação humana é concebida como um cálculo de prazeres e sofrimentos. Sobre a utilização da matemática, esta consiste na utilização do cálculo diferencial como uma forma de elucidar o comportamento individual, a partir das bases da filosofia moral estabelecidas.

Sobre os fundamentos que determinam o comportamento individual, Jevons conjuga de maneira significativa o utilitarismo com uma teoria econômica abstrata sobre o comportamento individual, passível de ser verificada empiricamente pelo método de médias. Quanto à questão da matemática, embora a posição de Jevons

\footnotetext{
9 A filosofia moral sobre a qual Jevons constrói sua argumentação sobre economia encontra-se em Bentham An Introduction to the Principles of Moral and Legislation. Segundo White (1994) o autor marginalista centra sua abordagem em uma filosofia utilitarista.
} 
e Jevons (1972) não deixe de ter fundamento, a introdução da mesma não apenas na economia como em qualquer outro ramo do conhecimento, necessita de qualificação adequada que será feita posteriormente.

Complementarmente às posições de Jevons e Jevons e Paul, o tratado de Jevons pode também ser interpretado como uma tentativa do autor de trazer a economia para uma condição de ciência pela proposição de uma redefinição da mesma e de uma metodologia alternativa. Complementando a visão dos autores em foco Mosselmans (1998) advoga que Jevons edifica um sistema reducionista de economia política que tem por base as leis fundamentais do pensamento derivadas empiricamente através das leis da natureza que dão ao cientista capacidade de raciocínio e o habilitam a fazer inferências sobre um determinado objeto.

Nesse sentido, a obra Theory of Political Economy também pode ser interpretada como um conjunto de hipóteses sobre o comportamento individual, formuladas de acordo com os critérios destacados em sua metodologia, na qual ganha destaque a aplicação do método dedutivo, a concordância com os fatos observados e a não contradição com as leis da natureza ou da mente.

Ao mesmo tempo, tal como exposto, toda e qualquer formulação deverá ser passível de verificação empírica. Apesar desta última etapa não ser contemplada, o autor demonstra otimismo quanto à validade de suas propostas teóricas, dado que estão de acordo com fatos e outros seguimentos da própria ciência e com as regras da lógica.

O fato do tratado de Jevons estar em um formato matemático deriva da concepção do autor de que a economia, por lidar com grandezas e complicadas relações, deve ter a ciência dos números em sua metodologia de investigação.

É no contexto dessa proposta de metodologia alternativa que emerge o princípio da utilidade. Esta é a hipótese fundamental que será a base para o desenvolvimento das demais. Sua construção tem por base o comportamento de um agente individual, de forma simples e precisa, prevalecendo, sobretudo, a lógica conjugada com a matemática.

Preliminarmente ao seu desenvolvimento, Jevons sente a necessidade de definir os elementos que o integram, os quais, normalmente, são deixados de lado nos livros de HPE. Assim, as grandezas tratadas no princípio da utilidade são:

- M: quantidade absoluta de um bem;

- $\mathrm{MT}^{-1}$ : quantidade utilizada de um bem por unidade de tempo; 
- U: efeito agradável que resulta de qualquer incremento desse estoque; uma quantidade infinitesimal fornecida por unidade de tempo;

- $\mathrm{MUT}^{-1}$ : tempo de efeito agradável produzido pela unidade de um bem por unidade de tempo;

- $\quad$ MUT $^{-1 *}$ T ou UM: variação do efeito agradável absoluto de um bem em um intervalo de tempo não especificado.

Jevons utiliza o símbolo M como uma grandeza física que expressa a massa de um determinado bem. Contudo, como já foi colocado, a quantidade absoluta representa muito pouco quando considerada isoladamente, ou seja, faz-se necessária a introdução do elemento tempo. Com isso, uma determinada quantidade de bens deve ser estimada de acordo com o tempo necessário para ser consumida.

Contudo, de acordo com a definição de economia e de teoria da utilidade, é fundamental introduzir, nas palavras de Jevons (1983), o efeito favorável do consumo em quantidades infinitesimais, dado por U. Jevons ressalta, no entanto, que essa variável não representa uma dimensão perfeita do estado de prazer e sofrimento.

Dessa forma, o produto MUT $^{-1}$ vai representar o efeito favorável de um bem por unidade de tempo. Porém, não é possível afirmar que esta grandeza seja a utilidade. Para tal, novamente é necessária a introdução do elemento T.

A grandeza da utilidade, dessa forma, é representada pela intensidade, definida por $\mathrm{MUT}^{-1}$, multiplicada pela duração T, para que seja possível ter-se a quantidade de prazer produzido. Com isso, o efeito agradável do consumo de um bem por unidade de tempo será igual a $\mathrm{MUT}^{-1 *} \mathrm{~T}$ ou $\mathrm{UM}^{10}$.

Considerando que o princípio da utilidade é o principal argumento de Jevons em sua formulação, Niehans (1990) afirma que a teoria do autor pode ser interpretada como a análise de um problema de otimização sobre o comportamento de um agente individual. Apesar deste ser objeto de outras ciências como a psicologia, igualmente pode ser tratado pela economia.

Niehans (1990) também observa que quando Jevons define a utilidade, chama atenção para o fato de que esta não é uma qualidade intrínseca de cada bem, mas uma relação que estes possuem com prazeres e sofrimentos de cada indivíduo.

10 É conveniente chamar atenção para o fato de que, embora reconheça a importância da variável tempo, Jevons, diante da formalização colocada, mostra a razão pela qual a mesma não está presente na teoria da utilidade. A introdução do elemento em foco, normalmente, leva à inclusão de um terceiro em sua teoria da utilidade: a incerteza. Em função dos objetivos propostos neste trabalho, um aprofundamento deste elemento é algo que não se faz necessário. 
Com isso, Jevons deixa clara a possibilidade de um bem ser completamente inútil de acordo com a quantidade (M) que um determinado agente disponha do mesmo, além ou aquém de sua necessidade ${ }^{11}$.

Com isso, Niehans (1990) chama atenção, no pensamento de Jevons, para a Lei da Variação da Utilidade que é introduzida pelo autor e que corresponde ao montante de utilidade (U), associado a uma determinada quantidade adicional consumida de um bem (UM). Contudo, o elemento fundamental é a utilidade comparativa entre as várias quantidades de um bem e a intensidade produzida sobre o agente econômico. Isto significa que, para variações constantes de quantidades, a utilidade será cada de vez menor ${ }^{12}$.

Feitas tais elucidações, para Niehans, o essencial no pensamento de Jevons é a variação do grau final de utilidade que será o ponto fundamental para tratar os demais problemas econômicos, como a teoria da troca, que o autor discute no restante de sua obra.

Stigler (1950a), concordando com Niehans, observa que Jevons não apenas reconhece a utilidade (U) como um fato da experiência apreendido por intuição, ou a partir de outras ciências, mas também a coloca como o princípio de todas as questões desenvolvidas ao longo de sua obra.

Para Stigler (1950a), a partir de sua exposição simples e didática sobre a variação da utilidade, Jevons reconhece que é necessário colocá-la em uma linguagem matemática apropriada, na qual é fundamental enfatizar os conceitos de utilidade total e o grau final de utilidade. Na formulação de Jevons, este último conceito -que posteriormente na literatura é chamado de utilidade marginal- constitui a base de todos os problemas econômicos.

De maneira geral, ainda segundo Stigler (1950b), o grau final de utilidade diminui, normalmente tendendo para zero, na medida em que a quantidade de um bem aumenta. Isto significa que, considerando $\Delta \mathrm{x}$ uma pequena variação na quantidade e $\Delta u$, na utilidade, pode-se medir o grau final de utilidade pela razão $\Delta u$ / $\Delta x$. Assim,

1 Esta observação de Niehans (1990) pode ser constatada quando Jevons (1871, p. 50) afirma: "Em primeiro lugar, a utilidade, apesar de ser uma qualidade das coisas, não é uma qualidade inerente. Defini-se melhor como uma circunstância das coisas que surge da relação destas com as exigências do homem."

12 Jevons (1871, p. 52) exemplifica esta observação de Niehans (1990) ao colocar que "... a utilidade total da comida que comemos é a de manter a vida, e pode ser considerada infinitamente grande; mas se subtrairmos 1/10 daquilo que comemos diariamente, nossa perda seria apenas leve. Certamente, não teríamos pedido $1 / 10$ da utilidade total que a comida tem para nós. É até duvidoso que soframos qualquer dado...Se sua comida faltar, a pessoa sentirá a necessidade de com nitidez; a retirada de uma terceira parte será sem dúvida prejudicial; com cada retirada sucessiva das partes restantes seus sofrimentos serão mais e mais sérios, até que finalmente ela estará à beira da inanição." 
Jevons define o grau final de utilidade como o coeficiente diferencial, uma função de $\mathrm{x}, \mathrm{ou}$, em linguagem matemática mais refinada, $\mathrm{du} / \mathrm{dx} \mathrm{x}^{13}$.

A teoria da utilidade, tal como proposta por Jevons, constitui o primeiro e mais importante fundamento da Theory of Political Economy. De acordo com a proposta metodológica do autor, essa teoria está em formato simples e preciso, embora pouco formalizado. É de bom alvitre enfatizar que trata-se de uma hipótese sobre o comportamento econômico de um agente individual.

Nesta condição, o princípio da utilidade, no caso específico da proposição de Jevons em sua Theory of Political Economy, é uma conjectura que tem por base os fundamentos já edificados por outras ciências que versam sobre o comportamento humano e as regras da lógica com uma base matemática. Contudo, como o fundamento em tela é verificado empiricamente? A resposta para esta questão será objeto da próxima seção.

\section{O PRINCÍPIO DA UTILIDADE: PESQUISA EMPIRICA E TEORIA ECONÔMICA}

De acordo o que foi definido na introdução deste trabalho, este tem por objetivo analisar as proposições teóricas de Jevons do ponto de vista de suas propostas metodológicas, destacando o princípio da utilidade. Neste sentido, como caracterizar a hipótese proposta pelo autor expostas anteriormente no âmago de sua metodologia?

Tal como já discutido preteritamente, embora o pensamento de Jevons esteja colocado em sua obra Theory of Political Economy, na qual estabelece as bases fundamentais para a economia política, um entendimento adequado de seus fundamentos metodológicos requer uma análise sobre seu tratado de lógica: The Principles of Science.

O hiato de tempo entre o The Principles of Science e a Theory of Political Economy é de quatro anos, embora o resumo e a estrutura da segunda já estivessem delineados na década de 1860, devendo-se notar que ambas as obras refletem o grau de insatisfação de Jevons com as ideias correntes, tanto no plano da ciência do raciocínio como no da economia política.

No primeiro caso, o autor marginalista denuncia a desconexão entre o estado da arte da lógica com a prática dos cientistas. Nesse sentido, como já exposto,

13 Stigler faz utilização da mesma formalização de Jevons (1871, p. 53) que este coloca: "Contudo, como já foi explicado, a utilidade de um bem pode se tida como variando em continuidade perfeita, de forma que cometemos um pequeno erro ao supô-la constante em toda a extensão do acréscimo $\Delta x$. Para evitar isso, devemos imaginar um $\Delta x$ reduzido a um tamanho infinitamente pequeno, $e \Delta u$ acompanhando a redução. Quanto menores forem as quantidades, mais perto estaremos da expressão correta. Assim, o limite da fração $\Delta u / \Delta x$, ou, como é representado geralmente, $d u /$ $d x$, é o grau de utilidade correspondente à quantidade do bem x. grau final de utilidade é, em linguagem matemática, o coeficiente diferencial de u considerado como função de x, e será ele mesmo outra função de x." 
a concepção de método indutivo, tal como defendida por Bacon, Hume e Mill, estava completamente em desacordo com a maneira pela Jevons acreditava que os cientistas de sua época, em especial os físicos, atuavam na investigação de seu objeto de estudo.

Ao longo do capítulo primeiro de seu tratado sobre economia, tal como chama atenção Peart (1998), Jevons faz alusão ao The Principles os Science, destacando que, mais do que proposições de caráter teórico em contraposição aos economistas clássicos, fundamentalmente Mill, o objetivo do Theory of Political Economy é propor também uma nova metodologia de investigação para a ciência econômica.

Com isso, ainda seguindo Peart (1998), Jevons chama atenção explicitamente para a necessidade de um aprofundamento sobre determinados elementos que vão fazer parte da metodologia de investigação na economia em seu tratado sobre lógica. Dessa forma, o autor em tela quer chamar atenção para um conjunto de elementos fundamentais em seu The Principles of Science que poderiam ser incorporado nos processo de investigação em economia como a conjugação da indução com a dedução, e a utilização de hipóteses e do método de médias que será explorado nas páginas seguintes.

Em sua Theory of Political Economy, Jevons inicia sua abordagem, como já exposto, acusando J. S. Mill de ter encerrado determinadas discussões e, por consequência, ter inviabilizado um exame de novas teorias sobre economia política. Dessa forma, não é difícil perceber que, ao fazer uma proposição alternativa de uma ciência da economia política, Jevons tinha em mente algo que já fazia parte da prática dos cientistas, embora sem ter o devido tratamento por parte da lógica.

Com isso, para Jevons, a economia deveria se constituir em uma ciência indutiva, que conjuga em seu processo de investigação a indução e a dedução, tendo por base uma hipótese previamente elaborada. Contudo, em função de suas peculiaridades, tem um caráter singular em relação às outras ciências. Então, o que diferencia a referida ciência dos demais ramos do conhecimento?

Tal como discutido, para Jevons, o conhecimento científico se inicia e é concluído com a observação. Nas ciências analisadas pelo autor, o estágio inicial consiste na delimitação do objeto de estudo e na definição das variáveis que deverão ser estudadas. Inclui-se aí, também, um processo que visa à descoberta das leis que vão determinar a base empírica de uma ciência, as quais são formalizadas por meio de equações que traduzem a relação entre as variáveis estudadas.

No caso específico da economia, este processo primário de observação é algo que é prescindível, pelo fato de que a referida ciência constrói seus argumentos to- 
mando por base outras ciências que versam sobre o comportamento humano, como a psicologia. Quanto a isso, é importante relembrar que Jevons não deixa claro como as mesmas teriam edificado suas premissas. Dessa forma, todo processo preliminar de observação que tem por objetivo definir as bases empíricas da economia como ciência está fundamentado em outros ramos do conhecimento.

Ainda em sua proposta de investigação indutiva, conforme já observado, Jevons chama atenção para a complementaridade que existe entre as lógicas indutiva e dedutiva. No processo de pesquisa que propõe, chama atenção para a funcionalidade de ambas e afirma praticamente ao longo de todo o The Principles of Science que a dedução é a indução de forma invertida. É fundamental relembrar que, para Jevons, embora complementares, as respectivas lógicas são diferenciadas tanto em seus graus de dificuldade como nos resultados obtidos.

Nesse contexto, ao caracterizar a economia política, em função das peculiaridades da mesma, a lógica indutiva está implícita pelo fato de que, tal como colocado anteriormente, o processo preliminar de observação é uma etapa superada. Com isso, em seu tratado sobre economia - Theory of Political Economy - o que prevalece é a dedução e não sua lógica alternativa. Com isso, no que tange à obra Theory of Political Economy, de acordo com o que foi já observado, esta vai se configurar em um conjunto de hipóteses elaboradas a partir dos critérios mencionados anteriormente e que também deve ser confirmada também pela observação.

Caracterizada a obra Theory of Political Economy segundo as bases metodológicas do The Principles of Science, é possível agora discutir a teoria da utilidade proposta de Jevons na mesma perspectiva.

A teoria da utilidade é o primeiro e o mais importante fundamento sobre o comportamento econômico de um agente individual. Faz parte de um objetivo mais pretensioso de Jevons na construção de noções relativamente simples sobre o comportamento de um agente individual, as quais compõem a base sobre a qual toda e qualquer investigação em economia deve se fundamentar.

No contexto de sua proposta de lógica indutiva, o princípio da utilidade consiste em uma hipótese formulada de acordo com as leis que regem o comportamento humano, estando em formato simples e preciso caracterizado pela lógica e pela matemática, embora esta última esteja menos evidente. Jevons tem por escopo dar-lhe tratamento científico, aos moldes do que acontece nas ciências da natureza.

Contudo, mesmo levando em conta os fatos observados ou confirmados por outras ciências e a lógica, Jevons ainda assim insiste na verificação empírica de suas 
conjecturas pela utilização do método de médias ${ }^{14}$. Propositadamente, esta última parte foi deixada para esta seção.

Assim, como verificar empiricamente o princípio da utilidade dentro da lógica indutiva proposta por Jevons?

Ao longo de seu trabalho de economia, para todas as hipóteses formuladas pelo mesmo, Jevons deixa claro que existe necessidade de uma investigação numérica de suas hipóteses formuladas em seu tratado de economia através do método de médias. Porém, a fundamentação deste procedimento está em um nível maior de detalhes nos The Principles of Science.

Jevons (1877) argumenta que os resultados da mensuração de uma variável contínua podem ser apenas uma verdade aproximada. A falha reside no fato de que o teste das hipóteses correspondentes ocorre em circunstâncias diferentes. Mesmo quando se opera com o devido cuidado não se pode realizar um experimento ou uma observação simples sem que haja discrepância em termos de resultados.

Sobre a utilização do método de médias é pertinente fazer alusão à Mosselmans (1998) quando este chama atenção de que uma determinada hipótese colocada no tratado de economia de Jevons é verdadeira tanto na perspectiva de um agente individual como no agregado. Contudo, é pertinente destacar que, no caso do princípio da utilidade, o consumo de um determinado indivíduo pode não variar em quantidades infinitesimais em função do consumo de um determinado bem, porém é de se esperar que isso ocorra em nível agregado, onde o princípio permanece praticamente o mesmo.

Dessa forma, ainda seguindo Mosselmans (1998), um princípio como do da utilidade é verdadeiro tanto do ponto de vista individual como do agregado. No primeiro caso, apesar do reducionismo, este é verdadeiro por estar em de acordo com os fatos e com as regras da lógica e é passível de verificação empírica pelo método de médias. Com isso, pode-se concluir que o referido princípio depende muito mais dos resultados agregados do que do individual.

Dessa forma, a existência de erro em um método de medida pode ser considerada algo normal. Portanto, é impossível eliminar a um só tempo todo um conjunto de causas perturbadoras que existem no teste de uma determinada hipótese. Então,

14 Jevons (1983, p. 52) ao longo de toda sua obra faz alusão ao método de médias. Ao introduzir sua Teoria da Utilidade, o autor chama atenção para: "As leis que estamos prestes a delinear devem ser vistas como teoricamente verdadeiras com relação ao indivíduo, mas só podem ser verificadas na prática em relação a transações, produções e consumos agregados de grande número de pessoas. Contudo, é claro que as leis dos agregados dependem das leis referentes aos casos individuais." 
pela utilização do método de médias, existe a expectativa de se chegar a uma verdade aproximada (Jevons, 1877).

Como não é possível obter duas vezes o mesmo resultado, a questão que se coloca é como chegar à verdade ou selecionar um determinado resultado?

Ao responder esta indagação, Jevons (1877) afirma que não existe uma maneira infalível para se chegar à verdade, mas que, por meio do método de médias ${ }^{15}$, é possível alcançá-la, observando que esse tipo de processo pode ser aplicado na investigação científica com três finalidades: a eliminação de erros; a eliminação de causas perturbadoras; e a detecção dos efeitos de uma causa sobre um determinado objeto.

Em primeiro lugar, a eliminação de erros de fontes desconhecidas é quase sempre feita por meio de processos aritméticos, tomando por base a média. Esta constitui um resultado meramente representativo, pois expressa a magnitude geral de uma série de quantidades na comparação umas com outras, bem como permite fazer a simplificação hipotética de um problema e evitar as complexidades, sem necessariamente ocorrer em erros.

Em segundo lugar, as médias podem dar um resultado aproximado, livres de causas perturbadoras que afetam um resultado ${ }^{16}$.

Por fim, em terceiro lugar, os efeitos relativos das causas que atuam sobre um objeto podem ser detectados com grande margem de segurança a partir de uma série de observações de números, que devem ser suficientes para habilitar o investigador a contrapor um efeito ao outro. Para isso, é possível obter resultados pela utilização de médias das observações que atuam positiva e negativamente. Até mesmo como consequência dos dois argumentos anteriores, pode-se ter resultados mais ou menos normais, ou seja, livres do que é desconhecido, bem como daquilo que deriva da incerteza.

No caso específico da teoria da utilidade, ao ser submetida à verificação empírica, é necessário considerar um grupo de agentes. Inicialmente, para cada um, é dada a mesma quantidade de um bem de consumo. Em seguida, em uma nova

15 Jevons (1877, p. 358), sobre a questão do conhecimento e da busca da verdade, ao introduzir o método de médias, afirmou: "There is no infallible mode of arriving at the absolute truth, which lies beyond the reach of human intellect, and can only be the distant object o four long-continued and painful approximations. Nevertheless there is a mode pointed out alike by common sense and the highest mathematical reasoning, which is likely than any other, as a general rule, to bring us near the truth".

16 Jevons (1877, p. 359) foi enfático ao afirmar que: "It may give a result approximately free from disturbing quantities, which are known to affect some results in one direction, and other results equally in the opposite direction". 
distribuição do mesmo bem, haverá agentes que vão consumi-lo integralmente e outros, apenas em parte. Como não é possível saber o estado individual de cada um dos consumidores, pode-se validar a teoria em questão pela redução do consumo médio.

Com isso, Jevons chama atenção para o fato de que toda e qualquer formulação sobre o comportamento de um agente econômico seja elaborada para o mesmo individualmente, sua verificação empírica ocorre em um nível agregado pelo método de médias.

Esta última parte sobre a pesquisa sobre os fundamentos da economia política proposta por Jevons em sua obra Theory of Political Economy não é contemplada pelo autor. O autor reconhece que não havia dados para que uma hipótese como o princípio da utilidade fosse confirmada empiricamente. Contudo, o autor demonstra otimismo sobre a validade da mesma na medida em que esta tem por base os fundamentos de outras ciências que versam sobre o comportamento humano e, ao mesmo tempo, está de acordo com as regras da lógica conjugadas com a matemática.

\section{CONCLUSÃO}

O tratado de Jevons sobre economia constitui uma aplicação dos princípios de investigação indutiva propostos em seu The Principles of Science. Apesar das peculiaridades da economia em relação às demais ciências como a física, por exemplo, o autor demonstra em sua obra Theory of Political Economy a possibilidade de investigação dos fundamentos da mesma através da metodologia contida em seu tratado sobre lógica.

O princípio da utilidade é o primeiro e o mais importante fundamento proposto por Jevons em sua obra Theory of Political Economy. Do ponto de vista da proposta metodológica do autor, detalhada em seu tratado sobre lógica The Principles of Science, trata-se de uma hipótese que tem por base o comportamento de um agente individual.

Do ponto de vista da investigação indutiva proposta por Jevons em seu tratado sobre lógica, o princípio da utilidade é uma conjectura construída sobre duas perspectivas: a empírica e a lógica. No primeiro caso, se edifica sobre um conjunto de fatos observados e trabalhados por outras ciências. No segundo caso, fundamenta-se na aplicação do método dedutivo conjugado com a matemática. 
Jevons e o princípio da utilidade marginal: pesquisa empírica e teoria econômica

\section{BIBLIOGRAFIA}

Black, R. D. Collison (1972). W. S. Jevons Foundation of Modern Economics. Em: History of Political Economy, Vol. 4, No. 2, p. 364-378.

Black, R. D. Collison (Eds) (1981). Papers and Correspondences of William Stanley Jevons: Papers of Political Economy. The Macmillan Press, London, Great Britain, 265p.

Burris, Stanley N. (2001). The Logicians: From Richard Whately to William S. Jevons. University of Waterloo: Ontario, Canada, 354p.

Jevons, H. E. y Jevons, H (1972). Willian Stantley Jevons. Em: Econometrica, Vol. 2, No. 3, Jul., p. 225-237.

Jevons, W (1983). A Teoria da Economia Política. Abril Cultural: São Paulo, Brasil, Col. 'Os Economistas', 397p.

Jevons, W (1877). The Principles of Science. A Treatise on Logic and Scientific Method. University Press of Pacific: Hawaii, USA, 786p.

Keynes, J. M (1921). A Treatise on Probability. Dover Publications: Hawai, EUA, 466p.

Mill, J. S (1843). A System of Logic: Ratiocinative and Inductive: Being a Connected View of the Principles of Evidence and the Methods of Scientific Investigation, Volumen 1. New York, Harper \& Brothers, Publishers, 580p.

Mosselmans, Bert (1998). William Stanley Jevons and the extent of meaning in logic and economics. Em: History and Philosophy of Logic, Vol. 19, No. 2, p. 83-99.

Niehans, Jürg (1990). A History of Economic Theory. The Johns Hopkins University Press: London, Great Britain, 578p.

Paul, Ellen (1979). Willian Stantley Jevons Revolutionary Political Utilitarist. Em: Journal of History of Ideas, Vol. 40, No. 2, p. 267-283.

Peart, Sandra (1998). The economics of WS Jevons. Em: The Canadian Journal of Economics/Revue canadienne d'Economique, Vol. 31, No. 1 (Feb., 1998), pp. 240-242

Sampaio, W S (2008). Para Além da Utilidade Marginal: Uma Leitura Metodológica Alternativa de Jevons e Walras. Tese para optar ao título de doutor em economia, Universidade Federal do Rio de Janeiro, Brasil, 137p.

Schabas, Margaret (1998). Jevons. Em: DAVIS, John; HANDS, Wade; MAKI, Uskali. The Hand6ook of Economic Methodology. Edward Elgar: Vermont, EUA, 572p.

Stigler, George J (1950a). The Development of Utility Theory I. Em: The Journal of Political Economy, Vol. 58, No. 4, p-307-327.

Stigler, George J (1950b). The Development of Utility Theory II. Em: The Journal of Political Economy, Vol. 58, No. 5, p-373-396.

White, Michael V (1994). Bridging the Natural and the Social: Science and Character in Jevons's Political Economy. Em: Economic Inquiry, Vol. 32, No. 3, p. 429-444. 
